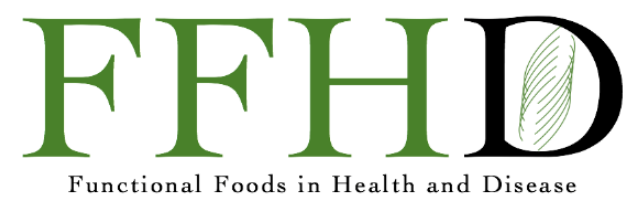

\title{
Biotic nutritional components in baby formula: possible solution for infantile colic management
}

\author{
Yulia Berezovskaya $^{1^{*}}$, Ksenia Varakina-Mitrail ${ }^{1}$, Viktoria Nechaeva² $^{2}$ Irina Kholodova² \\ ${ }^{1}$ Research and Development Department, MAMAKO ${ }^{\circledR}$ USA, LLC, Chicago, IL, USA; ${ }^{2}$ Department of Pediatrics \\ named after Academician G.N. Speransky, Russian Medical Academy of Continuous Postgraduate Education, \\ Moscow, Russia
}

*Corresponding Author: Yulia Berezovskaya, PhD, Research and Development Department, MAMAKO ${ }^{\circledR}$ USA, LLC, 1811 West Diehl Road, Suite 300, Naperville, IL 60563.

Submission Date: July $7^{\text {th }}, 2020$; Acceptance Date: August $4^{\text {th }}, 2020$; Publication Date: September $11^{\text {th }}, 2020$

Please cite this article as: Berezovskaya Y., Varakina-Mitrail K., Nechaeva V., Kholodova I. Biotic nutritional components in baby formula: possible solution for infantile colic management. Functional Foods in Health and Disease 2020. 10(9): 368-380, DOI: https://www.doi.org/10.31989/ffhd.v10i9.737

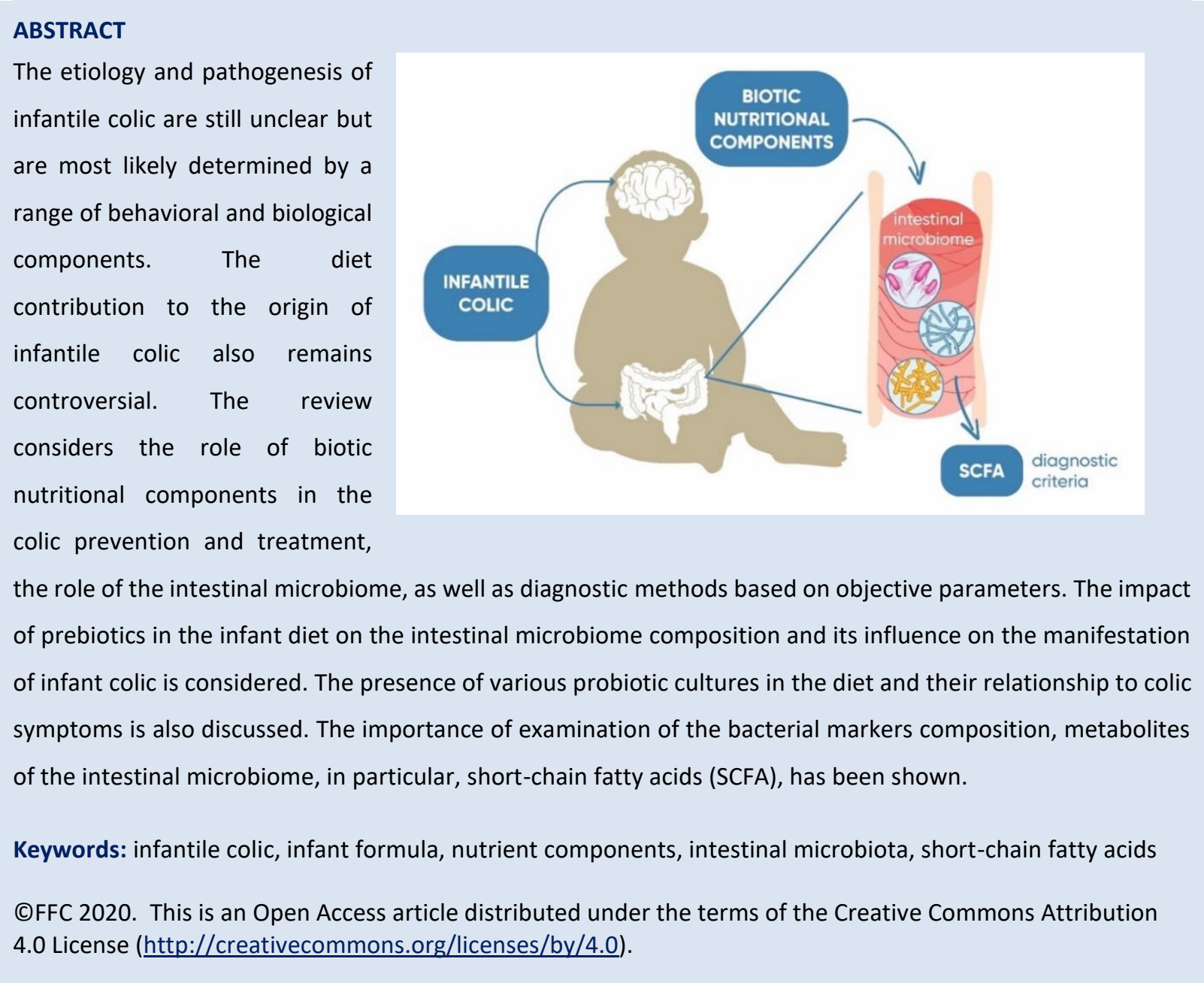




\section{INTRODUCTION}

Infantile colic is a common phenomenon affecting $5 \%$ to $20 \%$ of children worldwide [1-4]. Symptoms are manifested in infants under five months of age. These are prolonged periods of crying and irritability, occurring without any obvious reason and apparently associated with abdominal pain. These do not lead to any growth and developmental child's violations and are not associated with the development of diseases [5]. These symptoms do not cause significant harm and stop spontaneously upon a certain age acquisition [2].

Nevertheless, infantile colic is the reason for every fourth visit to a healthcare professional and an inexhaustible source of parental concerns. The causes of colic origin are not quite obvious. Gastrointestinal tract immaturity, allergies, intestinal cramping, and excessive gas formation due to improper nutrient composition - all these were considered among the reasons [6-8], along with psychosocial characteristics, for example, maternal anxiety and mother-child interaction problems [9]. There is an opinion that colic presents more frequent while breastfeeding than with the use of infant formulas, but there is no convincing evidence for this. According to modern views on the problem, colic is a gastrointestinal disorder caused by inflammatory processes in the intestine and microbial dysbiosis, which affect brain function [10].
For the colic treatment, a number of methods are proposed, including the use of herbal teas, soybased infant formulas, partially fermented, low lactose and fiber-enriched formulas, increased carrying, music, crib vibration, massage, and spinal manipulation; however, their effectiveness is questionable [11].

The etiology and management of infantile colic is the subject of numerous research studies and reviews. The respective keywords search in the PubMed database yields about 11 and a half thousand papers dating back to 1805 . The number of indexed publications has been growing rapidly since the beginning of the 1960s (1960 - 33 articles, 1970 - 57, and so on, up to 473 in 2019) (Fig. 1). However, a general consensus on treatment methods has not yet been obtained. Most authors agree that the probiotics and prebiotics content in children nutrition plays a significant role in the prevention and management of the disorder [1218]. Their composition and quantity determine the intestinal microbiome development - a community of microorganisms involved in the digestion process which crucially affects the result of this process. The microbiome can be considered as an organ within an organ that promotes the nutrition of the host, protection against pathogens and the immune response development.

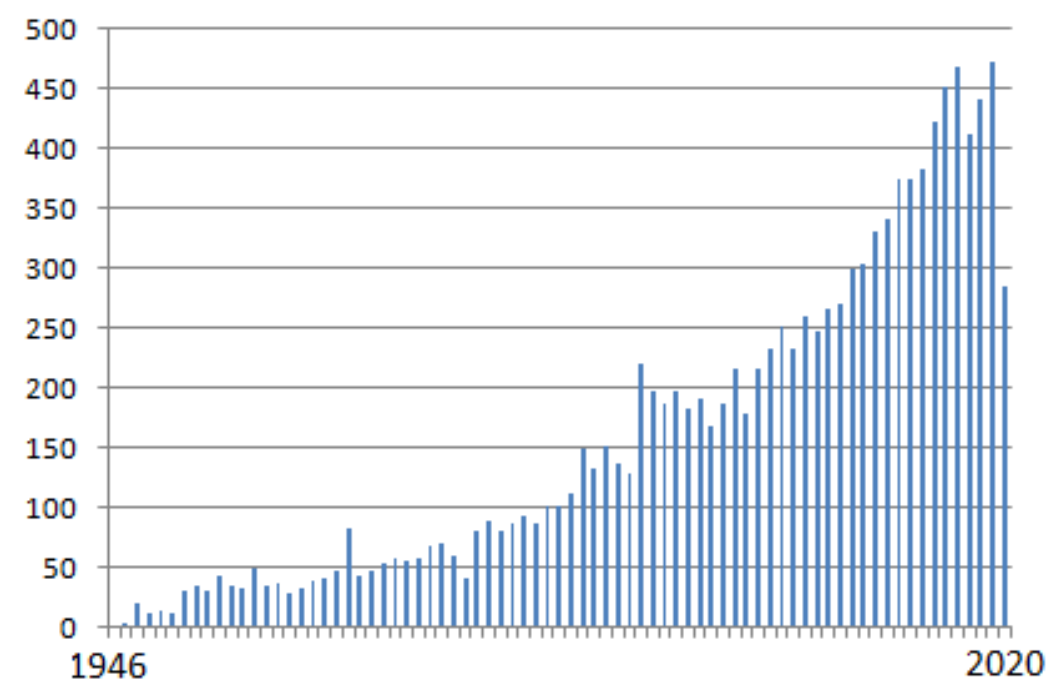

Figure 1. The growth in the number of publications indexed in the PubMed database by the key term "infantile colic" from 1946 to the present. 
Nutrient Components and Intestinal Microbiome After the baby's birth, the intestine colonization occurs gradually by various microorganisms provided with food, and soon bifidobacteria dominate in the intestinal microbiome of breastfed children [19-21]. Prebiotics are substances components of nutrition that stimulate the growth and/or activity of bacteria that establish beneficial symbiotic relationships with their host in the digestive system [22-23]. In particular, human milk oligosaccharides (HOS) selectively enhance the growth of bifidobacteria [24]. This is confirmed by the fact that Bifidobacterium longum subspecies infantis, a microorganism actively consuming these oligosaccharides, was found in the microbiota of breast-fed children almost everywhere around the world [25]. In addition, the intestinal microbiome of children who were fed a cow's milk-based formula without HOS showed a greater species diversity while fewer bifidobacteria [26-27]. HOS is the third component of human breast milk and is practically missing in cow's milk. It should be noted that typical amounts of oligosaccharides found in goat's milk is 4 to 5 times higher than those in cow's milk, although even this number is significantly lower compared to mature human breast milk [28]. It is known that breastfeeding is associated with a reduced risk of subsequent development of chronic non-communicable diseases (NCDs) including type II diabetes mellitus and obesity [29], but the intestinal microbiome effect on this relationship is not supported by any evidence.

Probiotics are living microorganisms, while administered adequately, are able to provide benefits to the host organism. Composition and activity modification of the intestinal microbiome by probiotics is currently recognized as the most relevant method for the gastrointestinal disorders treatment, in particular, infantile colic management. It is important to note that for a microbe to be recognized as a probiotic, the evidence-based health effects have to be demonstrated.
The probiotics modes of action are complex and not fully understood. It is often assumed that probiotics act by modulating the intestinal microbiota, but evidence for this hypothesis is rare, and the probiotics definition above does not refer to the intestinal microbiota. Specific probiotics have shown to be effective in the prevention and treatment of gastrointestinal upsets; for example, infantile diarrhea caused by antibiotics medication [30], but it is not obvious that these beneficial effects affect the intestinal microecology. Moreover, some clinical trials revealed that probiotic administration in pregnant and lactating mothers significantly reduces the incidence of atopic dermatitis in high-risk children without affecting the infantile intestinal microbiota composition [31].

A systematic analysis of 16 clinical trials which included 1319 newborns under the age of 6 months was performed recently by Skonieczna-Zydecka et al. [32]. Ten of the trials included L. reuteri DSM17938 strain administration, the duration of crying reduced with probiotics intervention (standard mean difference $=-2.012,95 \%$ confidence interval: from -2.763 to $-1.261, z=-5.25$, $p<0.0001)$. The probability of reducing crying duration by at least $50 \%$ was 1.98 times higher in the probiotic supplemented group than in the control $(Z=4.80, p<0.0001)$. The composition and functions of the intestinal microbiota and/or immunological markers were given in 11 studies. Probiotics were able to reduce crying duration significantly, but a cause-effect relationship between the modulating probiotic action on microbiota and the immune system has not been confirmed.

For the infantile colic treatment so-called synbiotics were proposed - according to the WHO definition, "mixtures of probiotics and prebiotics that beneficially affect the host by improving the survival and implantation of live microbial dietary supplements in the gastrointestinal tract of the host" [33]. A study of 50 breast-fed children with a 
synbiotic intervention (L. casei, L. rhamnosus, S. thermophiles, B. breve, L. acidophilus, B. infantis, L. bulgaricus strains and fructooligosaccharides) or placebo for 30 days showed that treatment efficacy was significantly higher in the synbiotic group compared to placebo on days 7 and 30 [34]. In another study with 60 colic children, the effect of an infant formula containing B. lactis BB12 and galactooligosaccharides with a reduced lactose content and partially hydrolyzed whey protein on daily crying duration was compared to a standard formula [35]. During a month period of the study, daily crying duration significantly decreased in the group of children that received synbiotic compared to the standard mixture fed group.

Indeed, breastfeeding is the best nutrition for infants. Babies who are breast-fed for a longer period are less susceptible to infections, develop better, and show better performance on intelligence tests than those who are breast-fed for shorter periods or are formula-fed. This inequality persists throughout their whole lives. There is growing evidence that breastfeeding can protect against overweight and diabetes later in life. However, in recent decades, especially in developed countries, the breastfeeding period has decreased and many children are exclusively formula-fed [29].

The infant formula manufacturers attempt to approximate to the greatest possible extent the product composition to the composition of breast milk or even improve it with a range of additives. Is there a correlation between the formula composition and the infantile colic and other digestive disorders risk? Obviously, there is, however, this relationship is not direct, studies show that diet changes do not always lead to improvements and so far there are no clear guidelines for the use of a particular diet [13].

The infant formula supplementation with proand prebiotics nowadays is a routine practice to the majority of manufacturers. According to review data provided by Skorka et al. [36], based on five clinical study analyses, the probiotics Bifidobacterium lactis BB12 addition alone or with Streptococcus thermophilus did not affect growth, respiratory infections, antibiotic use, frequency or consistency of stool. However, there was a significant decrease in the number of gastrointestinal infections (BB12) episodes and colic or irritability frequency (when both strains were used).

Lactobacillus johnsonii La1 strain did not affect growth, gastrointestinal infections, or respiratory disease episodes. No effects of probiotics addition with Bifidobacterium longum BL999, alone or with Lactobacillus rhamnosus LPR, were observed. L. rhamnosus GG supplementation was associated with better growth; while this did not affect colic/crying or irritability and was associated with higher rates of loose stools and a higher defecation frequency. Lactobacillus reuteri ATCC 55730 did not affect growth, colic, crying, irritability, respiratory infections, antibiotic use, stool frequency, or consistency; however, this reduced the incidence of diarrhea.

L. reuteri DSM 17938 did not affect growth, night sleep, or flatulence, but reduced regurgitation incidence. Lactobacillus salivarius CEC5713 did not affect growth, colic, crying, or irritability; however, this led to a significant reduction in diarrhea incidence and the respiratory symptoms episodes frequency. The administration of probiotic mixtures to healthy children does not give rise to concerns regarding growth or side effects. However, as regards to the use of specific probiotics strains, most researchers find it difficult to come to unambiguous conclusions. Specifically, L. reuteri DSM 17938, recently often proposed for the colic management [12], shows a good outcome for breastfed children but does not show the same effectiveness with formula feeding [37-39]. A general review of clinical trials concerning various aspects of pro- and prebiotics use (not only as components of baby food, but also as medications, etc.) was published by Brüssow [40], and their use 
in pediatric practice is reviewed by Vandenplas \& Savino [41].

While mother's milk is rich in HOS prebiotics and contains a small number of probiotic bacteria, the classic infant formula does not contain these components. Infant formula manufacturers often add various prebiotic oligosaccharides mimicking HOS: short-chain galacto-oligosaccharides, longchain fructo-oligosaccharides (Fig. 2), polydextrose

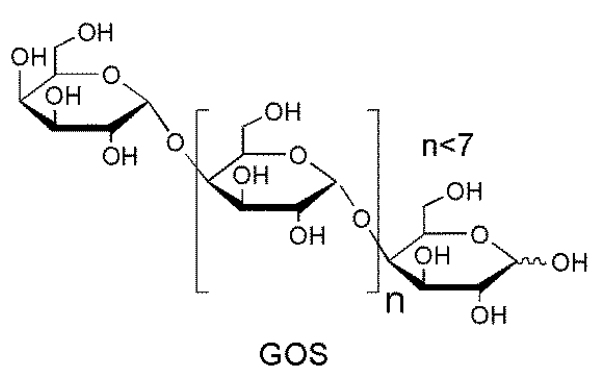

and the mixtures thereof. There is evidence that prebiotics supplementation of baby formula changes the intestinal microbiome, making it closer to the one that forms while breastfeeding. Infants who received these supplements had lower stool $\mathrm{pH}$, better stool consistency and frequency, and a higher intestinal bifidobacterium content compared to children who received a standard mixture without supplements [42-43].

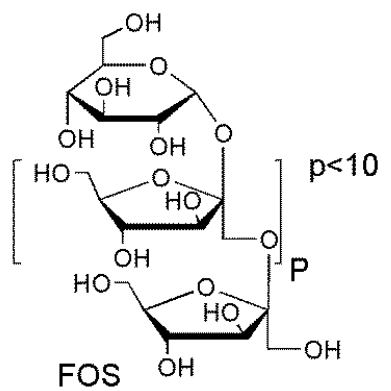

Figure 2. Galacto-oligosaccharides (GOS) and fructo-oligosaccharides (FOS) structures.

Generally, the term "-biotics" refers to nutritional components that can be used to direct intestinal microbiome development in a mode more favorable for the host health. The recent term "postbiotics" refers to biologically active compounds produced by food microorganisms during the fermentation process: short-chain fatty acids, functional proteins, extracellular polysaccharides, teichoic acid, and peptidoglycan derivatives. Postbiotics also include microbial cells, cellular components, lysates, and metabolites. The part of the effects manifested by the pre- and probiotics use caused precisely by the formation of these metabolic byproducts of microorganisms. The effects and mechanisms of postbiotics action, as well as the possibilities of their use, are reviewed by Wegh et al. [44]. Postbiotics are present in partially fermented baby formulas, a relatively new type of formulas for infant feeding [45-46]. As shown by a clinical study [47], feeding with this type of formula, enriched by additional prebiotic oligosaccharides, significantly reduces infantile colic incidence. The study involved 432 healthy fullterm babies aged 0-28 days, whose mothers decided not to start breastfeeding or terminated.
Fermented infant formula supplemented by prebiotics was well tolerated and showed a lower total crying time, lower colic rate, and softer stools. However, a similar study [48], involved 241 children, on the contrary, showed that crying time was significantly shorter in the control group where children received standard formula than in the group fed partially fermented formula with low lactose quantity containing L. reuteri DSM 17938.

Significant uncertainty and even contradictions in the results of various studies of the nutrition effect on infantile colic manifestations are largely due to the fact that the methods of assessment are based on subjective indicators (parental surveys, etc.). While it is possible to use objective control methods to determine microbiome content, accurate register for parameters such as crying duration or level of irritation is absolutely impossible. In addition, the causes of these manifestations may be distinct, not associated with colic - for example, allergies or gastrointestinal reflux, or even the inexperience of an adult caregiver.

Recently, different approaches were taken to link intestinal microbiome composition and 
development with colic manifestation for objective study and diagnosis. There is no definitive understanding of how unbalanced intestinal colonization or intestinal dysbiosis can contribute to infantile colic symptoms. However, researchers assumed that the presence of a significant number of pathogenic bacteria causes a chronic inflammatory response. As a response, intestinal epithelial tissue release cytokines and chemokines both locally and systemically, which additionally cause inflammation and local nerve tissues sensitization [49-50].

\section{Microbiome and Colic - The Search For Objective}

Connections: Traditional microbiological approaches based on cultivation and phenotypic observations are not well adapted for the intestinal microbiome study. Nowadays, genomic technologies dominate which allow to determine and classify microorganisms with high accuracy by conservative fragments of their genetic sequence 16S rRNA and rDNA. A range of studies estimated the relationship between microbiome composition and colic manifestations, results are summarized by Dubois et al. review [51]. Briefly, the study showed that children with severe colic symptoms had significantly higher Proteobacteria levels in the microbiome and showed lower bacterial diversity compared to healthy ones. In addition, the colonization levels for Actinobacteria Bifidobacterium and Firmicute Lactobacilli showed an inverse relationship with crying and irritation parameters in newborns.

A comprehensive screening of metabolites by NMR analysis, conducted in parallel with a PCR study of feces, was carried out in a clinical study of the efficacy and safety of a mixture of probiotics proposed for infantile colic treatment [52]. The study included 53 children, the group taking probiotics showed a significant decrease in the number of colic manifestations in comparison to the control. No differences were found between the groups with respect to anthropometric data, intestinal motility, stool consistency, or microbiota composition. It was found that probiotics affect the fecal molecular profile.

The mixture studied was an oil suspension of medium-chain triglycerides containing a lyophilized highly concentrated probiotic mixture with several lactobacilli strains (L. paracasei DSM 24733, L. plantarum DSM 24730, L. acidophilus DSM 24735 and L. delbrueckii subsp. bulgaricus DSM 24734) three bifidobacteria strains (B. longum DSM 24736, B. breve DSM 24732 and B. infantis DSM 24737) and one strain of Streptococcus thermophilus DSM 24731. To quantify bifidobacteria and lactobacilli in the stool qPCR was used with gene-specific primers. All fecal samples were also subjected to $1 \mathrm{H} \mathrm{NMR}$ analysis, the assignment of signals in the NMR spectrum was done by comparing their chemical shift and multiplicity with the human metabolome database [53] and the Chenomx software library (Chenomx Inc., Edmonton, AB, Canada, ver 8.1).

The data obtained confirmed the hypothesis that the effect of the probiotic on the intestinal microbiome may include not only changes in the intestinal bacteria composition but also play a key role in intestinal bacterial metabolism. Despite the fact that probiotic supplements did not change the number of lactobacilli and bifidobacteria in the microbiome of infants, the fecal molecular profile differed between groups. In the placebo group, the alanine concentrations and two acids, 2hydroxyisovalerianic and 2-oxoisocaproic, which are involved in the metabolism of valine, leucine, and isoleucine, were significantly increased. The data obtained confirmed the hypothesis that the effect of the probiotic on the intestinal microbiome may include not only changes in the intestinal bacteria composition but also play a key role in intestinal bacterial metabolism. In addition, significantly higher levels of acetic acid, one of the main short-chain fatty acids (SCFAs) produced during microbiota fermentation were found in the placebo group. Acetic acid level increase in feces is associated with gastrointestinal symptoms 
deterioration in adult patients with irritable bowel syndrome [54]. Propylene glycol appeared to be one of the most striking biomarkers found in the probiotic group. Propylene glycol is a characteristic component present in the feces of newborns, its higher concentration was found in feces of breastfed children, compared with those fed with the formula [55]. This may be related to an increase in the lactaldehyde reductase activity, which uses HOS as a substrate. Thus, an increase in propylene glycol concentration may indicate a more "normal" microbiome development. The metabolic approaches in above-mentioned and several other clinical trials of pro- and prebiotics efficacy and safety were discussed in the O'Connell review [56].

Another approach is based on the study of bacterial markers content - metabolites and postbiotics characteristic for certain groups of bacteria. This approach allows to make a general estimation of gastrointestinal tract colonization by different microorganism types, without clarifying the exact microbiome composition. It is rather simple in terms of interpreting the results. This approach was applied in studies [57-58] when the microbiome state was evaluated by short-chain fatty acids content in stools - metabolic products of probiotic lactobacilli and bifidobacteria. These postbiotics' role for the processes of intestinal epithelial cells functioning is comprehensive [59], it is not limited to local effects - short-chain fatty acids have a systemic effect on the host organisms. Acetic, propionic, and butyric acids account for 90$95 \%$ of the SCFA present in the intestine [60]. The approximate molar ratios of acetate: propionate: butyrate are 60:20:20, and although the absolute concentrations of SCFA may vary in different regions of the intestine, the molar ratios remain constant.

The main sources of SCFA are carbohydrates (including oligosaccharides), but amino acids valine, leucine, and isoleucine resulting from protein breakdown are also converted to isobutyrate, isovalerate, and 2-methylbutyrate - branched-chain SCFA which account for about $5 \%$ of the SCFA produced by the microbiome. The metabolic pathways of SCFA formation (Fig. 3) by intestinal microbiome are discussed in detail in reviews by Rios-Covian et al. [61] and Rawi et al. [62] and McNeil et al. [63].

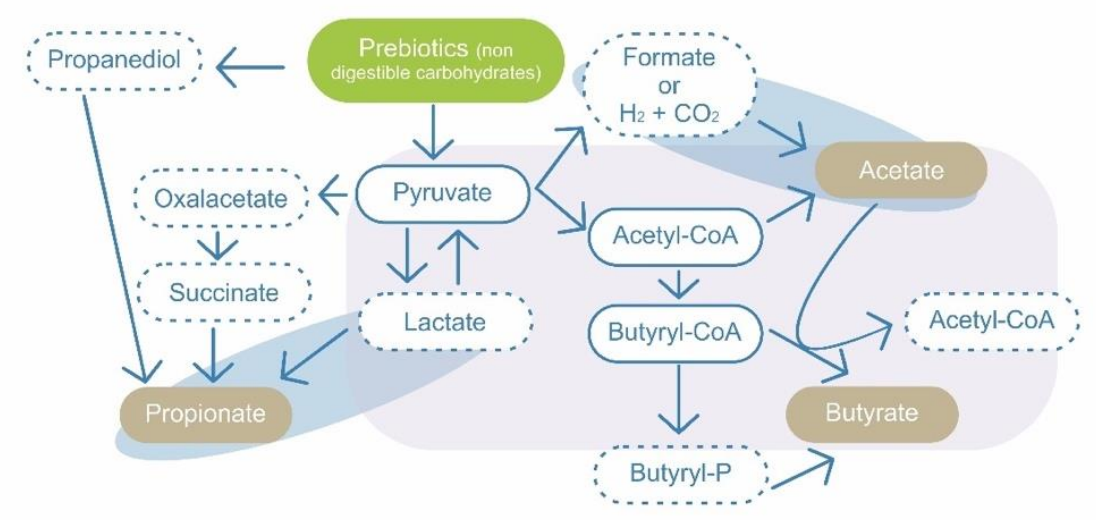

Figure 3. Schematic representation of microbial metabolic pathways, contributing to SCFA formation in the human gut. Shaded geometric shapes summarize routes of formation for each of the three main SCFA: acetate, propionate, and butyrate [61].

The $95 \%$ of produced SCFAs are absorbed in the intestines, providing approximately $5-10 \%$ of human energy needs [63]. Providing extra calories, SCFAs support energy homeostasis. SCFAs affect cell proliferation and differentiation and can cause hormone secretion $[60 ; 64]$. SCFAs also modulate inflammatory processes and can affect some functions of white blood cells, they inhibit pro- 
inflammatory production, among them TNF- $\alpha$, IL-6, and NO. Butyrate may enhance the release of the anti-inflammatory cytokine IL-10. SCFAs are associated with leukocyte chemotaxis, which promotes their migration to the inflammation site [65-67].

In recent years, evidence has emerged that the effect of SCFAs on the central nervous system serves as a link between the intestinal microbiome and the brain [68-69]. Methods for determining short-chain fatty acids are very simple, do not require access to high technology, and therefore, in the future, with the accumulation of pooled analysis data sufficient to establish correlation, they can serve to diagnose disorders of the development of the microbiome.

\section{CONCLUSION}

It can be considered proven that infantile colic manifestation is directly related to the type of nutrition and intestinal microbiome development. Unequivocal recommendations and standards do not exist at the moment, but the consensus regarding the importance of pro- and prebiotic components in nutrition is forming. The objective research methods elaboration allows us to expect the development of effective methods for the colic diagnosis and treatment in the nearest future.

List of abbreviations: SCFA: short chain fatty-acid, NMR: nuclear magnetic resonance, PCR: polymerase chain reaction.

Competing Interests: The authors have no financial interests or conflicts of interest.

Authors' contribution: All authors contributed to this study.

Acknowledgment and Funding: The authors declare no acknowledgments or funding.

\section{REFERENCES}

1. Lucassen P.L., Assendelft W.J., van Eijk J.T., Gubbels J.W., Douwes A.C., van Geldrop W.J. Systematic review of the occurrence of infantile colic in the community // Arch Dis Child. 2001. T. 84. № 5. - C. 398-403.

2. Sarasu J.M., Narang M., Shah D. Infantile Colic: An Update // Indian Pediatr. 2018. T. 55. № 11. - C. 979987.
3. Perry R., Leach V., Penfold C., Davies P. An overview of systematic reviews of complementary and alternative therapies for infantile colic // Syst Rev. 2019. T. 8. № 1. - C. 271.

4. Sung V. Infantile colic // Aust Prescr. 2018. T. 41. № 4. -C. 105-110.

5. Hyman P.E., Milla P.J., Benninga M.A., Davidson G.P., Fleisher D.F., Taminiau J. Childhood functional gastrointestinal disorders: neonate/toddler // Gastroenterology. 2006. T. 130. № 5. - C. 1519-26.

6. Camilleri M., Park S.Y., Scarpato E., Staiano A. Exploring hypotheses and rationale for causes of infantile colic // Neurogastroenterol Motil. 2017. T. 29. № 2.

7. Daelemans S., Peeters L., Hauser B., Vandenplas $Y$ Recent advances in understanding and managing infantile colic // F1000Res. 2018. T. 7.

8. Zeevenhooven J., Browne P.D., L'Hoir M.P., de Weerth C., Benninga M.A. Infant colic: mechanisms and management // Nat Rev Gastroenterol Hepatol. 2018. T. 15. № 8. - C. 479-496.

9. Vik T., Grote V., Escribano J., Socha J., Verduci E., Fritsch M., Carlier C., von Kries R., Koletzko B., European Childhood Obesity Trial Study G. Infantile colic, prolonged crying and maternal postnatal depression // Acta Paediatr. 2009. T. 98. № 8. - C. 1344-8.

10. Mai T., Fatheree N.Y., Gleason W., Liu Y., Rhoads J.M. Infantile Colic: New Insights into an Old Problem // Gastroenterol Clin North Am. 2018. T. 47. № 4. - C. 829-844.

11. Drug, Therapeutics B. Management of infantile colic // BMJ. 2013. T. 347. - C. f4102.

12. Szajewska H., Dryl R. Probiotics for the Management of Infantile Colic // J Pediatr Gastroenterol Nutr. 2016. T. 63 Suppl 1. № 1S. - C. S22-4.

13. Gordon M., Biagioli E., Sorrenti M., Lingua C., Moja L., Banks S.S., Ceratto S., Savino F. Dietary modifications for infantile colic // Cochrane Database Syst Rev. 2018. T. 10. - C. CD011029.

14. Ong T.G., Gordon M., Banks S.S., Thomas M.R., Akobeng A.K. Probiotics to prevent infantile colic // Cochrane Database Syst Rev. 2019. T. 3. - C. CD012473.

15. Schreck Bird A., Gregory P.J., Jalloh M.A., Risoldi Cochrane Z., Hein D.J. Probiotics for the Treatment of Infantile Colic: A Systematic Review // J Pharm Pract. 2017. T. 30. № 3. - C. 366-374.

16. Partty A., Rautava S., Kalliomaki M. Probiotics on Pediatric Functional Gastrointestinal Disorders // Nutrients. 2018. T. 10. № 12.

17. Sung V. Probiotic interventions in infantile colic // 
Curr Opin Clin Nutr Metab Care. 2015. T. 18. № 3. C. $307-11$

18. Hjern A., Lindblom K., Reuter A., Silfverdal S.A. A systematic review of prevention and treatment of infantile colic // Acta Paediatr. 2020.

19. Roger L.C., Costabile A., Holland D.T., Hoyles L., McCartney A.L. Examination of faecal Bifidobacterium populations in breast- and formulafed infants during the first 18 months of life // Microbiology. 2010. T. 156. № Pt 11. - C. 3329-3341.

20. Tannock G.W., Lawley B., Munro K., Gowri Pathmanathan S., Zhou S.J., Makrides M., Gibson R.A., Sullivan T., Prosser C.G., Lowry D., Hodgkinson A.J. Comparison of the compositions of the stool microbiotas of infants fed goat milk formula, cow milk-based formula, or breast milk // Appl Environ Microbiol. 2013. T. 79. № 9. - C. 3040-8.

21. Milani C., Duranti S., Bottacini F., Casey E., Turroni F., Mahony J., Belzer C., Delgado Palacio S., Arboleya Montes S., Mancabelli L., Lugli G.A., Rodriguez J.M., Bode L., de Vos W., Gueimonde M., Margolles A., van Sinderen D., Ventura M. The First Microbial Colonizers of the Human Gut: Composition, Activities, and Health Implications of the Infant Gut Microbiota // Microbiol Mol Biol Rev. 2017. T. 81. № 4.

22. Roberfroid M., Gibson G.R., Hoyles L., McCartney A.L., Rastall R., Rowland I., Wolvers D., Watzl B., Szajewska H., Stahl B., Guarner F., Respondek F., Whelan K., Coxam V., Davicco M.J., Leotoing L., Wittrant Y., Delzenne N.M., Cani P.D., Neyrinck A.M., Meheust A. Prebiotic effects: metabolic and health benefits $/ / \mathrm{Br}$ J Nutr. 2010. T. 104 Suppl 2. - C. S1-63.

23. Wei X., Fu X., Xiao M., Liu Z., Zhang L., Mou H. Dietary galactosyl and mannosyl carbohydrates: In-vitro assessment of prebiotic effects // Food Chem. 2020. T. 329. - C. 127179.

24. Musilova S., Rada V., Vlkova E., Bunesova V. Beneficial effects of human milk oligosaccharides on gut microbiota // Benef Microbes. 2014. T. 5. № 3. - C. 273-83.

25. Underwood M.A., German J.B., Lebrilla C.B., Mills D.A. Bifidobacterium longum subspecies infantis: champion colonizer of the infant gut // Pediatr Res. 2015. T. 77. № 1-2. - C. 229-35.

26. Azad M.B., Konya T., Maughan H., Guttman D.S., Field C.J., Chari R.S., Sears M.R., Becker A.B., Scott J.A., Kozyrskyj A.L., Investigators C.S. Gut microbiota of healthy Canadian infants: profiles by mode of delivery and infant diet at 4 months // CMAJ. 2013. T. 185. № 5. - C. 385-94.

27. Azad M.B., Konya T., Persaud R.R., Guttman D.S., Chari R.S., Field C.J., Sears M.R., Mandhane P.J., Turvey S.E., Subbarao P., Becker A.B., Scott J.A.,
Kozyrskyj A.L., Investigators C.S. Impact of maternal intrapartum antibiotics, method of birth and breastfeeding on gut microbiota during the first year of life: a prospective cohort study // BJOG. 2016. T. 123. № 6. - C. 983-93.

28. Martinez-Ferez A., Rudloff S., Guadix A., Henkel C.A., Pohlentz G., Boza J.J., Guadix E.M., Kunz C. Goats' milk as a natural source of lactose-derived oligosaccharides: Isolation by membrane technology // International Dairy Journal. 2006. T. 16. № 2. - C. 173-181.

29. Victora C.G., Bahl R., Barros A.J., Franca G.V., Horton S., Krasevec J., Murch S., Sankar M.J., Walker N., Rollins N.C., Lancet Breastfeeding Series G. Breastfeeding in the 21st century: epidemiology, mechanisms, and lifelong effect // Lancet. 2016. T. 387. № 10017. - C. 475-90.

30. Hayes S.R., Vargas A.J. Probiotics for the Prevention of Pediatric Antibiotic-Associated Diarrhea // Explore (NY). 2016. T. 12. № 6. - C. 463-466.

31. Dotterud C.K., Avershina E., Sekelja M., Simpson M.R., Rudi K., Storro O., Johnsen R., Oien T. Does Maternal Perinatal Probiotic Supplementation Alter the Intestinal Microbiota of Mother and Child? // J Pediatr Gastroenterol Nutr. 2015. T. 61. № 2. - C. 200-7.

32. Skonieczna-Zydecka K., Janda K., Kaczmarczyk M., Marlicz W., Loniewski I., Loniewska B. The Effect of Probiotics on Symptoms, Gut Microbiota and Inflammatory Markers in Infantile Colic: A Systematic Review, Meta-Analysis and Meta-Regression of Randomized Controlled Trials // J Clin Med. 2020. T. 9. № 4.

33. http://www.fao.org/3/a-a0512e.pdf (accessed on 09.07.2020)

34. Kianifar H., Ahanchian H., Grover Z., Jafari S., Noorbakhsh Z., Khakshour A., Sedaghat M., Kiani M. Synbiotic in the management of infantile colic: a randomised controlled trial // J Paediatr Child Health. 2014. T. 50. № 10. - C. 801-5.

35. Xinias I., Analitis A., Mavroudi A., Roilides I., Lykogeorgou M., Delivoria V., Milingos V., Mylonopoulou M., Vandenplas Y. Innovative Dietary Intervention Answers to Baby Colic // Pediatr Gastroenterol Hepatol Nutr. 2017. T. 20. № 2. - C. 100-106.

36. Skorka A., Piescik-Lech M., Kolodziej M., Szajewska H. To add or not to add probiotics to infant formulae? An updated systematic review // Benef Microbes. 2017. T. 8. № 5. - C. 717-725.

37. FitzGibbon K., Ju N.R. Can the Probiotic Lactobacillus reuteri Be Used to Treat Infant Colic? // Ann Emerg Med. 2019. T. 73. № 3. - C. 272-273. 
38. Sung V., D'Amico F., Cabana M.D., Chau K., Koren G., Savino F., Szajewska H., Deshpande G., Dupont C., Indrio F., Mentula S., Partty A., Tancredi D. Lactobacillus reuteri to Treat Infant Colic: A Metaanalysis // Pediatrics. 2018. T. 141. № 1.

39. St James-Roberts I. Is It Time To Recommend Lactobacillus for Colic? Not Necessarily // Pediatrics. 2018. T. 141. № 1

40. Brussow H. Probiotics and prebiotics in clinical tests: an update // F1000Res. 2019. T. 8.

41. Vandenplas Y., Savino F. Probiotics and Prebiotics in Pediatrics: What Is New? // Nutrients. 2019. T. 11. № 2.

42. Vandenplas Y., De Greef E., Veereman G. Prebiotics in infant formula // Gut Microbes. 2014. T. 5. № 6. - C. 681-7.

43. Bertelsen R.J., Jensen E.T., Ringel-Kulka T. Use of probiotics and prebiotics in infant feeding // Best Pract Res Clin Gastroenterol. 2016. T. 30. № 1. - C. 39-48.

44. Wegh C.A.M., Geerlings S.Y., Knol J., Roeselers G., Belzer C. Postbiotics and Their Potential Applications in Early Life Nutrition and Beyond // Int J Mol Sci. 2019. T. 20. № 19.

45. Szajewska H., Skorka A., Piescik-Lech M. Fermented infant formulas without live bacteria: a systematic review // Eur J Pediatr. 2015. T. 174. № 11. - C. 141320.

46. van de Heijning B.J., Berton A., Bouritius H., Goulet O. GI symptoms in infants are a potential target for fermented infant milk formulae: a review // Nutrients. 2014. T. 6. № 9. - C. 3942-67.

47. Vandenplas Y., Ludwig T., Bouritius H., Alliet P., Forde D., Peeters S., Huet F., Hourihane J. Randomised controlled trial demonstrates that fermented infant formula with short-chain galacto-oligosaccharides and long-chain fructo-oligosaccharides reduces the incidence of infantile colic // Acta Paediatr. 2017. T. 106. № 7. - C. 1150-1158.

48. Turco R., Russo M., Bruzzese D., Staiano A. Efficacy of a partially hydrolysed formula, with reduced lactose content and with Lactobacillus reuteri DSM 17938 in infant colic: A double blind, randomised clinical trial // Clin Nutr. 2020.

49. DeVon H.A., Piano M.R., Rosenfeld A.G., Hoppensteadt D.A. The association of pain with protein inflammatory biomarkers: a review of the literature // Nurs Res. 2014. T. 63. № 1. - C. 51-62.

50. Rhoads J.M., Collins J., Fatheree N.Y., Hashmi S.S., Taylor C.M., Luo M., Hoang T.K., Gleason W.A., Van Arsdall M.R., Navarro F., Liu Y. Infant Colic Represents Gut Inflammation and Dysbiosis // J Pediatr. 2018. T. 203. - C. 55-61 e3.
51. Dubois N.E., Gregory K.E. Characterizing the Intestinal Microbiome in Infantile Colic: Findings Based on an Integrative Review of the Literature // Biol Res Nurs. 2016. T. 18. № 3. - C. 307-15.

52. Baldassarre M.E., Di Mauro A., Tafuri S., Rizzo V., Gallone M.S., Mastromarino P., Capobianco D., Laghi L., Zhu C., Capozza M., Laforgia N. Effectiveness and Safety of a Probiotic-Mixture for the Treatment of Infantile Colic: A Double-Blind, Randomized, PlaceboControlled Clinical Trial with Fecal Real-Time PCR and NMR-Based Metabolomics Analysis // Nutrients. 2018. T. 10. № 2.

53. Wishart D.S., Tzur D., Knox C., Eisner R., Guo A.C., Young N., Cheng D., Jewell K., Arndt D., Sawhney S., Fung C., Nikolai L., Lewis M., Coutouly M.A., Forsythe I., Tang P., Shrivastava S., Jeroncic K., Stothard P., Amegbey G., Block D., Hau D.D., Wagner J., Miniaci J., Clements M., Gebremedhin M., Guo N., Zhang Y., Duggan G.E., Macinnis G.D., Weljie A.M., Dowlatabadi R., Bamforth F., Clive D., Greiner R., Li L., Marrie T., Sykes B.D., Vogel H.J., Querengesser L. HMDB: the Human Metabolome Database // Nucleic Acids Res. 2007. T. 35. № Database issue. - C. D521-6.

54. Tana C., Umesaki Y., Imaoka A., Handa T., Kanazawa M., Fukudo S. Altered profiles of intestinal microbiota and organic acids may be the origin of symptoms in irritable bowel syndrome // Neurogastroenterol Motil. 2010. T. 22. № 5. - C. 512-9, e114-5.

55. Phan M., Momin S.R., Senn M.K., Wood A.C. Metabolomic Insights into the Effects of Breast Milk Versus Formula Milk Feeding in Infants // Curr Nutr Rep. 2019. T. 8. № 3. - C. 295-306.

56. O'Connell T.M. The Application of Metabolomics to Probiotic and Prebiotic Interventions in Human Clinical Studies // Metabolites. 2020. T. 10. № 3.

57. Kholodova I.N., Titova T.A., Kudayarova L.R., Kulakova G.A., Nechaeva V.V., Fetisova T.G., Zheltukhina M.V. Formulae based on goat's milk: their possible use in feeding infants during the first months of life // Practicheskaya Medicina. 2017. T. 111. № 10. - C. 35-42 (in Russian).

58. Zakharova I.N., Kholodova I.N., Bragin A.I., Nechaeva V.V. Nutrition of a healthy child during the first year of life: Is it all evident and do we know it all? // Medicinskiy Sovet. 2017. № 9. - C. 9-13 (in Russian).

59. Koh A., De Vadder F., Kovatcheva-Datchary P., Backhed F. From Dietary Fiber to Host Physiology: Short-Chain Fatty Acids as Key Bacterial Metabolites // Cell. 2016. T. 165. № 6. - C. 1332-1345.

60. Mortensen P.B., Clausen M.R. Short-chain fatty acids in the human colon: relation to gastrointestinal health and disease // Scand J Gastroenterol Suppl. 1996. T. 216. - C. 132-48. 
61. Rios-Covian D., Ruas-Madiedo P., Margolles A., Gueimonde M., de Los Reyes-Gavilan C.G., Salazar N. Intestinal Short Chain Fatty Acids and their Link with Diet and Human Health // Front Microbiol. 2016. T. 7. - C. 185

62. Rawi M.H., Zaman S.A., Pa'ee K.F., Leong S.S., Sarbini S.R. Prebiotics metabolism by gut-isolated probiotics // J Food Sci Technol. 2020. T. 57. № 8. - C. 27862799.

63. McNeil N.I. The contribution of the large intestine to energy supplies in man // Am J Clin Nutr. 1984. T. 39. № 2. - C. 338-42.

64. Tazoe H., Otomo Y., Kaji I., Tanaka R., Karaki S.I., Kuwahara A. Roles of short-chain fatty acids receptors, GPR41 and GPR43 on colonic functions // J Physiol Pharmacol. 2008. T. 59 Suppl 2. - C. 251-62.

65. Park J., Wang Q., Wu Q., Mao-Draayer Y., Kim C.H. Bidirectional regulatory potentials of short-chain fatty acids and their G-protein-coupled receptors in autoimmune neuroinflammation // Sci Rep. 2019. T. 9. № 1. - C. 8837 .

66. Ratajczak W., Ryl A., Mizerski A., Walczakiewicz K., Sipak O., Laszczynska M. Immunomodulatory potential of gut microbiome-derived short-chain fatty acids (SCFAs) // Acta Biochim Pol. 2019. T. 66. № 1. C. 1-12.

67. Soldavini J., Kaunitz J.D. Pathobiology and potential therapeutic value of intestinal short-chain fatty acids in gut inflammation and obesity // Dig Dis Sci. 2013. T. 58. № 10. - C. 2756-66.

68. Silva Y.P., Bernardi A., Frozza R.L. The Role of ShortChain Fatty Acids From Gut Microbiota in Gut-Brain Communication // Front Endocrinol (Lausanne). 2020. T. 11. - C. 25.Dalile B., Van Oudenhove L., Vervliet B., Verbeke K.The role of short-chain fatty acidsinmicrobiota-gut-braincommunication // Nat Rev Gastroenterol Hepatol. 2019. T. 16. № 8. - C. 461-478. 